\title{
The Association Between Achieving Low-Density Lipoprotein Cholesterol (LDL-C) Goal and Statin Treatment in an Employee Population
}

\author{
Wayne N. Burton, M.D., ${ }^{1}$ Chin-Yu Chen, Ph.D., ${ }^{2}$ Alyssa B. Schultz, Ph.D., ${ }^{2}$ and Dee W. Edington, Ph.D. ${ }^{2}$
}

\begin{abstract}
Statin medications are recommended for patients who have not achieved low-density lipoprotein cholesterol (LDL-C) goals through lifestyle modifications. The objective of this retrospective observational study was to examine statin medication usage patterns and the relationship with LDL-C goal levels (according to Adult Treatment Panel III guidelines) among a cohort of employees of a major financial services corporation.

From 1995 to 2004, a total of 1607 executives participated in a periodic health examination program. An index date was assigned for each study participant (date of their exam) and statin medication usage was determined from the pharmacy claims database for 365 days before the index date. Patients were identified as adherent to statins if the medication possession ratio was $\geq 80 \%$.

In all, 150 (9.3\%) executives filled at least 1 statin prescription in the 365 days prior to their exam. A total of 102 statin users $(68 \%)$ were adherent to statin medication. Among all executives who received statin treatment, $70 \%$ (odds ratio $[\mathrm{OR}]=2.30,95 \%$ confidence interval $[\mathrm{CI}]=1.82,2.90)$ achieved near-optimal $(<130 \mathrm{mg} / \mathrm{dL})$ and $30 \%$ $(\mathrm{OR}=1.78,95 \% \mathrm{CI}=1.15,2.76)$ achieved optimal $(<100 \mathrm{mg} / \mathrm{dL}) \mathrm{LDL}-\mathrm{C}$ goals, which is significantly higher than the rates among statin nonusers (55\% and $21 \%$ ). Adherent statin users were more likely to achieve recommended near-optimal LDL-C goals compared to statin nonusers (overall $P=0.002$; adherent: $\mathrm{OR}=2.75,95 \% \mathrm{CI}=1.662$, 4.550), while nonadherent statin users were more likely to achieve the optimal goal compared to statin nonusers $(\mathrm{OR}=2.223 ; \mathrm{CI}=1.145,4.313)$.

Statin usage was associated with improvements in LDL-C goal attainment among executives who participated in a periodic health examination. Appropriate statin medication adherence should be encouraged in working populations in order to achieve LDL-C goals. (Population Health Management 2010;13:1-8)
\end{abstract}

C ORONARY HEART DISEASE (CHD) is the leading cause of death for both men and women in the United States, accounting for an estimated $\$ 422.5$ billion in direct and indirect costs in 2008. ${ }^{1}$ The expert panel of the National Cholesterol Education Panel (NCEP) recommended HMG-CoA reductase inhibitor (statin) medications for patients who have not achieved low-density lipoprotein cholesterol (LDL-C) treatment goals through lifestyle modifications. ${ }^{2}$ Several studies have demonstrated the benefits of reductions in LDL-C in patients with and without CHD to decrease cardiovascular events. $3,4,5,6,7,8,9$ It appears that a $10 \%$ reduction in LDL-C over 10 years will result in at least a $10 \%$ reduction in CHD risk. ${ }^{9}$ Among Americans age 20 and older, the following have an LDL-C of $130 \mathrm{mg} / \mathrm{dL}$ or higher: $31.7 \%$ of nonHispanic $(\mathrm{NH})$ white men and $33.8 \%$ of $\mathrm{NH}$ white women;
$32.4 \%$ of $\mathrm{NH}$ black men and $29.8 \%$ of $\mathrm{NH}$ black women; $39 \%$ of Mexican American men and 30.7\% of Mexican American women. ${ }^{10}$ However studies have shown that many patients have not achieved their LDL-C treatment goals even when they are taking a statin medication. ${ }^{11,12,13,14,15,16,17}$

Little information exists regarding the use of statins or other cholesterol-lowering medications among employed populations. It is likely that a substantial proportion of workers with known elevated blood cholesterol do not receive appropriate medications. An early review by Nash found that fewer than one third of patients with diagnosed dyslipidemia tend to receive appropriate therapy. ${ }^{18}$ More recent studies of employed populations indicate better results. A variety of worksite disease management programs have tried to address the problem of patients not attaining

\footnotetext{
${ }^{1}$ University of Illinois at Chicago, Chicago, Illinois.

${ }^{2}$ University of Michigan Health Management Research Center, Ann Arbor, MI.
} 
cholesterol goal in order to achieve cardiovascular risk reduction. In general, the problem of achieving cholesterol goal can be attributed to provider factors and patient factors. ${ }^{19}$ Physicians must identify patients based on risk and be aggressive in efforts for their patients to achieve goal. ${ }^{20}$ For example, physicians in general have been found not to titrate the dose of a lipid-lowering medication to an appropriate goal. ${ }^{11,21}$ Similarly, for a variety of reasons, patients are not adherent with cholesterol-lowering medication. A recent Cochrane Collaboration reviewed interventions to improve adherence to lipid-lowering medication. ${ }^{22}$

The primary objectives of the current study include (1) characterizing a cohort of employees of a major financial services corporation using blood lipid values from annual or biannual health examinations; (2) examining usage patterns of cholesterol-lowering medications; and (3) studying the relationship between treatment with medication and achieving the recommended lipid level goals.

\section{Methods}

\section{Study population selection}

This is a retrospective observational analysis of data from one of the largest financial services companies in the United States. At the end of 2004 this financial services corporation had approximately 75,000 employees located in 25 states. This firm installed an integrated health data management system in 1987, which includes medical, pharmacy, and short-term disability claims data as well as personnel, wellness program participation, occupational medical records, and laboratory testing, among other data sets. ${ }^{23}$ All data utilized in this study were linked and de-identified prior to export to the University of Michigan Health Management Research Center (Ann Arbor, MI) for analyses. This study was conducted in accordance with the University of Michigan's Institutional Review Board.

The selected study population included executives who participated in a periodic health examination (PHE) program at the corporate headquarters from 1995 to 2004. Examinations, performed either annually or biannually, included a complete physical examination by a board certified internist, and comprehensive fasting laboratory tests including blood lipids. During this period, a total of 1607 executives had 3892 physical examinations that included a complete lipid profile (ie, total cholesterol, LDL-C, high-density lipoprotein cholesterol, triglycerides) information. Laboratory tests were performed by venipuncture after at least an 8-hour fast by Quest Diagnostics, Inc. (Wood Dale, IL). A previous study of the PHE provides more detailed information about the content of the exams. ${ }^{24}$ The executives were all enrolled in the corporation's self-insured medical plans and pharmacy benefits in the year of and the year before the examination to ensure that an identification period and at least a 12-month pre-index period were available.

To study the effect of antihyperlipidemic agents on lipid profile, each individual's last examination date was designated as the index date. Medication prescriptions were tracked 365 days prior to the index date. In general, medications were prescribed by the employee's personal doctor who, on occasion, may have been one of the examining doctors. The executives were divided into 2 groups. Statin users were those who had at least 1 statin prescription filled during the year prior to their exam, while statin nonusers were the executives who did not have a statin prescription filled during the year prior to their exam.

\section{Data extraction from pharmacy and medical claims}

Medications were identified by using National Drug Codes from the pharmacy claims of each year from 1994 to 2005. Antihyperlipidemic agents include HMG CoA reductase inhibitors (statins: eg, Atorvastatin, Cerivastatin, Fluvastatin, Lovastatin, Pravastatin, Rosuvastatin, Simvastatin), cholesterol absorption inhibitors (eg, Ezetimibe), and miscellaneous agents (eg, resins, fibrates, niacins). The current study focused only on statins because they were the dominant choice of pharmaceutical regimen for treating dyslipidemia in this population over the study period.

The number of days with a supply of a statin was summed from all filled prescriptions starting from the first date of any statin dispensed during the period of 365 days prior to index date and the index date. Medication possession ratio (MPR) was then calculated by dividing the summed days with a statin supply by the total number of days from the date of the first prescription until the examination date. A MPR $\geq 80 \%$ is considered adherent to the medication prescribed. ${ }^{25}$

A chronic disease score (CDS), based on the presence of prescription medications for 29 chronic conditions, was calculated from the pharmacy claims data for each participant. The CDS is a weighted summary measure of the comorbid conditions of the participants that is assessed from their prescription medication combination. ${ }^{26}$ Four digits of the American Hospital Formulary System (AHFS4) were applied to classify prescriptions into different categories. Employees who filled prescriptions with an AHFS4 of 6820 (antidiabetic agents) were classified as diabetic patients. Patients were classified as having heart diseases if their medical claims in the same pre-index period included International Classification of Diseases, Ninth Revision codes of 410-414 and 420-429.

\section{Setting LDL-C goals}

As the Adult Treatment Panel III guidelines ${ }^{2}$ suggested, 2 goals were set for the entire population: 1) LDL-C less than $100 \mathrm{mg} / \mathrm{dL}$ as the optimal goal, and 2) LDL-C less than $130 \mathrm{mg} / \mathrm{dL}$ as the near-optimal goal.

\section{Statistical analyses}

Group differences between statin users and nonusers regarding demographic and health conditions in the pre-index period were first examined by using $\chi^{2}$ tests for categorical variables and $t$ tests for continuous measures. Multiple logistic regression models were constructed to study the association with statin usage, taking into account each subject's demographic characteristics, preexisting conditions, and year of index date.

Another set of multiple logistic regression models were constructed to model the odds of achieving the 2 LDL-C goals at the time of index examination for pre-index period statin users and nonusers. The full model contained: 4 demographic factors (age, sex, ethnicity, work location); 3 health condition factors in the pre-index period (CDS score, presence of heart disease medical claims, use of diabetes medications); year of the index examination; and the indicator variables for any statin usage and statin treatment adherence. The significance 
of potential interactions between age and sex with other factors was also tested but only main effects were reported in final models. Odds ratios (OR) and their 95\% confidence interval (CI) limits were estimated for all variables in the models. All analyses were conducted using SAS 9.0 software (SAS Institute Inc., Cary, NC).

\section{Results}

The indexed physical examinations were selected from each employee's last examination during the period from 1995 to 2004. The number and percentage of these 1607 executives who received a statin prescription in each index year are shown in Table 1. The statin usage rate increased among this population as more statins became available, their safety was demonstrated, and outcomes research indicated the potential benefits of reducing cardiovascular disease morbidity and mortality over the study period.

The characteristics of the study population are presented in Table 2. PHE participants were $63 \%$ male and had an average age of 49.1 years in the index year of their physical examinations. In all, 150 (9.3\%) of all PHE participants had a statin prescription in the 365 days prior to the exam. This statin user population was more likely to be male and older, with an average of 54.3 years, compared with the statin nonuser PHE participants. No significant differences were found between PHE participants with and without a statin prescription with regard to ethnicity and work location.

In the pre-index period, statin users had a significantly higher CDS compared to statin nonusers, 1.68 and 0.44 respectively. A total of $4.7 \%$ of the statin users also took diabetes medication compared with only $0.8 \%$ of statin nonusers who took diabetes medicines. A greater percentage $(15.3 \%)$ of statin users had a medical claim for heart disease compared to the statin nonusers $(1.4 \%)$. These differences between statin users and nonusers remained significant even after controlling for confounding factors in the multiple logistic regression model (Table 3).

Among all PHE participants who received a statin prescription, $70 \%$ achieved the near-optimal LDL-C goal $(<130 \mathrm{mg} / \mathrm{dL})$ and $30 \%$ of them even achieved the optimal

Table 1. Distribution of Employees Who Received Statin Treatment in the Pre-Index Period by Year of the Executive Physical Examination

\begin{tabular}{lrrrr}
\hline & & & \multicolumn{2}{c}{ Any statin treatment } \\
\cline { 3 - 5 } & & & & \\
& $N$ & $\%$ of All & $N$ & $(\%)$ \\
\hline All patients & 1607 & $100.0 \%$ & 150 & $9.3 \%$ \\
Index year & & & & \\
1995 & 197 & $12.3 \%$ & 5 & $2.5 \%$ \\
1996 & 244 & $15.2 \%$ & 13 & $5.3 \%$ \\
1997 & 89 & $5.5 \%$ & 6 & $6.7 \%$ \\
1998 & 86 & $5.4 \%$ & 3 & $3.5 \%$ \\
1999 & 108 & $6.7 \%$ & 5 & $4.6 \%$ \\
2000 & 119 & $7.4 \%$ & 19 & $16.0 \%$ \\
2001 & 105 & $6.5 \%$ & 14 & $13.3 \%$ \\
2002 & 92 & $5.7 \%$ & 15 & $16.3 \%$ \\
2003 & 170 & $10.6 \%$ & 26 & $15.3 \%$ \\
2004 & 397 & $24.7 \%$ & 44 & $11.1 \%$ \\
\hline
\end{tabular}

LDL-C goal $(<100 \mathrm{mg} / \mathrm{dL})$, which is significantly greater than the $55 \%$ and $21 \%$ achieved respectively by statin nonusers. Figure 1 displays these results.

A multiple logistic regression model was constructed to further explore the characteristics of patients who were more likely to achieve their near-optimal and optimal LDL-C goals. Included explanatory variables are demographics (age, sex, ethnicity, work location), year of the index examination, health condition indicators (CDS, existing heart diseases or diabetes), and an indicator of whether statin treatment was given prior to the examination. As seen in Table 3, females were less likely $(\mathrm{OR}=0.272)$ to receive statin treatment compared to males, but Table 4 shows that females were 2.3 times more likely to achieve the near-optimal goal and 2.4 times more likely to achieve the optimal LDL-C goal compared to males. Older individuals were less likely to achieve their goals. Patients with existing heart disease also were more likely to achieve their LDL-C goal; diabetic patients were not as likely to achieve LDL-C goal. After adjusting for confounding factors, patients who received statin treatment were 2 times more likely to achieve their LDL-C goals. The OR of achieving the near-optimal LDL-C goal is 2.326 with $95 \%$ CI of 1.541 and 3.513 , and the OR of achieving optimal LDL-C goal is 1.783 with $95 \%$ CI of 1.153 and 2.755 .

Figure 2 shows the OR and 95\% CI of achieving nearoptimal and optimal LDL-C goals by patients who received statin treatment. Regardless of the different LDL-C target goals, the OR of achieving the goal by employees under statin treatment are about double the chance of those without statin treatment.

Of 150 statin users, $102(68 \%)$ had a MPR $\geq 80 \%$ during the pre-index period and were considered to be adherent to the treatment. In Table 5, the ORs of achieving the near-optimal and optimal LDL-C goal by adherence to statins are presented. Even after controlling for confounding variables, adherence to statins was significantly associated with achievement of the near-optimal LDL-C goal $(\mathrm{OR}=2.750)$ but not the optimal LDL-C goal $(\mathrm{OR}=1.561)$. Those who were not adherent to statins were significantly more likely to achieve the optimal LDL-C goal $(\mathrm{OR}=2.223)$ than those who did not take statins.

\section{Discussion}

This study, conducted in a large financial services organization, found that statin usage increased in this employed executive population over the study time period of 1994 to 2005. It further demonstrates the value of linking laboratory and pharmacy databases in order to focus on outcomes of a pharmacotherapy. Our data warehouse allows us to link an individual employee's medication history from the pharmacy benefit manager with laboratory lipid panel results. Linking lipid medication history with LDL-C laboratory values demonstrates that simply prescribing a medication clearly does not result in the desired outcome without careful monitoring and medication modification that includes titrating initial medication as well as switching to higher efficacious medications. All too often an employee is started on a lipid-lowering medication by a health care provider but receives little follow-up to determine if the employee reaches his or her LDL-C goal. Among all employees who received statin treatment, $70 \%$ and $30 \%$ achieved near-optimal 
Table 2. Characteristics of Executive Physical Examination Participants with Regard to Statin Usage in the Pre-Index Period

\begin{tabular}{|c|c|c|c|c|c|c|c|}
\hline & \multicolumn{2}{|c|}{ All study patients } & \multicolumn{2}{|c|}{ Took any statin } & \multicolumn{2}{|c|}{ Did not take statin } & \multirow[b]{2}{*}{$\operatorname{Pr}>$ Chi-Square ${ }^{*}$} \\
\hline & $N$ & $\%$ & $N$ & $\%$ & $N$ & $\%$ & \\
\hline Number of Employees & 1607 & $100.0 \%$ & 150 & $9.3 \%$ & 1457 & $90.7 \%$ & \\
\hline $\begin{array}{l}\text { Female } \\
\text { Male }\end{array}$ & $\begin{array}{r}592 \\
1015\end{array}$ & $\begin{array}{l}36.8 \% \\
63.2 \%\end{array}$ & $\begin{array}{r}19 \\
131\end{array}$ & $\begin{array}{l}12.7 \% \\
87.3 \%\end{array}$ & $\begin{array}{l}573 \\
884\end{array}$ & $\begin{array}{l}39.3 \% \\
60.7 \%\end{array}$ & $<.0001$ \\
\hline Mean age (SD), years & 49.1 & $(7.6)$ & 54.3 & $(6.7)$ & 48.6 & $(7.5)$ & $<.0001$ \\
\hline $\begin{array}{l}\text { Ethnicity } \\
\text { White } \\
\text { Black } \\
\text { Hispanic } \\
\text { Asian }\end{array}$ & $\begin{array}{r}1457 \\
72 \\
28 \\
50\end{array}$ & $\begin{array}{r}90.7 \% \\
4.5 \% \\
1.7 \% \\
3.1 \%\end{array}$ & $\begin{array}{r}141 \\
6 \\
1 \\
2\end{array}$ & $\begin{array}{r}94.0 \% \\
4.0 \% \\
0.7 \% \\
1.3 \%\end{array}$ & $\begin{array}{r}1316 \\
66 \\
27 \\
48\end{array}$ & $\begin{array}{r}90.3 \% \\
4.5 \% \\
1.9 \% \\
3.3 \%\end{array}$ & 0.3220 \\
\hline $\begin{array}{l}\text { Work location } \\
\text { Illinois } \\
\text { Ohio } \\
\text { Others }\end{array}$ & $\begin{array}{r}1176 \\
347 \\
84\end{array}$ & $\begin{array}{r}73.2 \% \\
21.6 \% \\
5.2 \%\end{array}$ & $\begin{array}{r}103 \\
41 \\
6\end{array}$ & $\begin{array}{r}68.7 \% \\
27.3 \% \\
4.0 \%\end{array}$ & $\begin{array}{r}1073 \\
306 \\
78\end{array}$ & $\begin{array}{r}73.6 \% \\
21.0 \% \\
5.4 \%\end{array}$ & 0.6373 \\
\hline $\begin{array}{l}\text { Health condition } \\
\text { Chronic disease score (SD) } \\
\text { Had heart disease claims } \\
\text { Took diabetes medication }\end{array}$ & $\begin{array}{l}0.56 \\
44 \\
18\end{array}$ & $\begin{array}{c}(1.52) \\
2.7 \% \\
1.1 \%\end{array}$ & $\begin{array}{l}1.68 \\
23 \\
7\end{array}$ & $\begin{array}{r}(2.04) \\
15.3 \% \\
4.7 \%\end{array}$ & $\begin{array}{l}0.44 \\
21 \\
11\end{array}$ & $\begin{array}{c}(1.41) \\
1.4 \% \\
0.8 \%\end{array}$ & $\begin{array}{l}<.0001 \\
<.0001 \\
0.1268\end{array}$ \\
\hline
\end{tabular}

*Multiple logistic regression (see Table 4) after confounding factors were adjusted.

$(<130 \mathrm{mg} / \mathrm{dL})$ and optimal $(<100 \mathrm{mg} / \mathrm{dL})$ goals for LDL-C, which is significantly more than the $55 \%$ and $21 \%$ achieved by statin nonusers. After adjusting for confounding factors, employees who received statin treatment were 2 times more likely to achieve their goals than employees who did not receive statin treatment. Moreover, those who were adherent to statins were significantly more likely to achieve the re- commended LDL-C goal than those who were not adherent with the medication.

There are relatively few published studies that specifically focus on the results of workplace cholesterol screening programs, although lipid laboratory tests are commonly performed in the United States as part of employer wellness programs. In an Australian cholesterol intervention program,

Table 3. Odds Ratios and 95\% Confidence Intervals of Executives Who Received Statin Therapy

\begin{tabular}{|c|c|c|c|c|}
\hline \multirow[b]{2}{*}{ Explanatory variables } & \multirow[b]{2}{*}{ Odds ratio of receiving treatment } & \multicolumn{2}{|c|}{ 95\% confidence limits } & \multirow[b]{2}{*}{$\operatorname{Pr}>$ Chi-square } \\
\hline & & Low & High & \\
\hline Female* & 0.272 & 0.161 & 0.461 & $<.0001$ \\
\hline Age in index year* & 1.107 & 1.076 & 1.140 & $<.0001$ \\
\hline White & 1.514 & 0.666 & 3.442 & 0.3220 \\
\hline Work in Illinois & 1.112 & 0.714 & 1.732 & 0.6373 \\
\hline \multicolumn{5}{|l|}{ Index year* } \\
\hline 1995 & 1.000 & & & \\
\hline 1996 & 1.985 & 0.675 & 5.836 & 0.0343 \\
\hline 1997 & 1.321 & 0.363 & 4.804 & \\
\hline 1998 & 0.766 & 0.165 & 3.552 & \\
\hline 1999 & 1.179 & 0.312 & 4.450 & \\
\hline $2000^{*}$ & 3.954 & 1.342 & 11.644 & \\
\hline 2001 & 2.440 & 0.781 & 7.623 & \\
\hline 2002 & 3.151 & 1.001 & 9.920 & \\
\hline $2003^{*}$ & 4.066 & 1.452 & 11.386 & \\
\hline 2004 & 2.677 & 1.010 & 7.094 & \\
\hline \multicolumn{5}{|l|}{ Health condition } \\
\hline $\mathrm{CDS}^{*}$ & 1.283 & 1.164 & 1.414 & $<.0001$ \\
\hline Had heart disease claims* & 5.931 & 2.925 & 12.029 & $<.0001$ \\
\hline Took diabetes medication & 2.477 & 0.773 & 7.937 & 0.1268 \\
\hline
\end{tabular}

*Significant at $P<0.05$.

CDS, chronic disease score. 


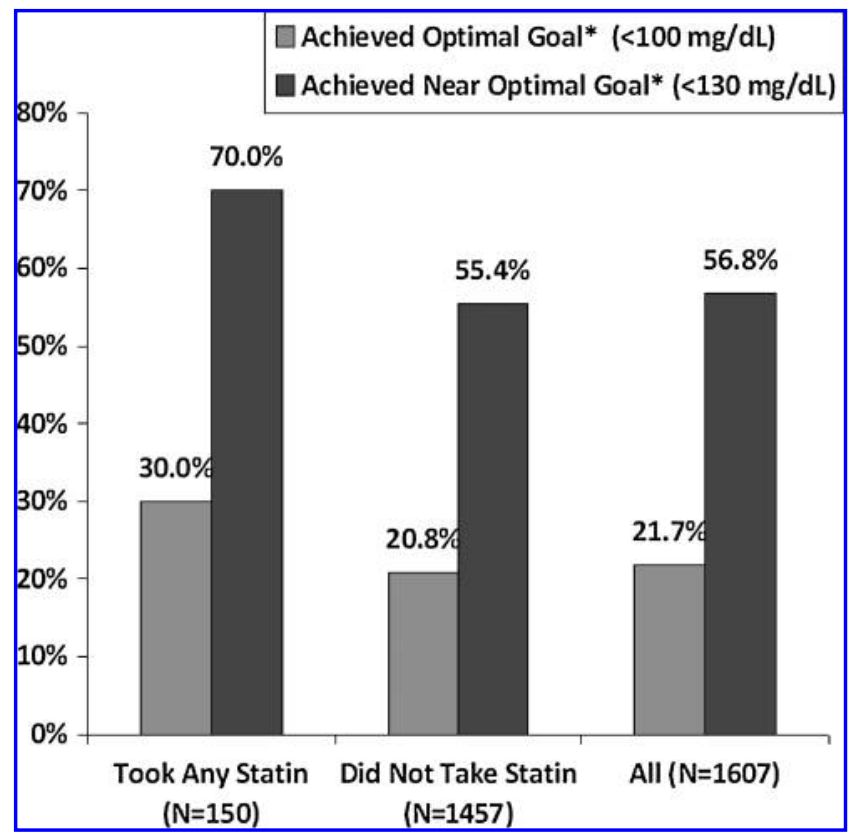

FIG. 1. The association of LDL-C goal achievement with statin therapy in pre-index period. ${ }^{*}$ Chi-square test between statin users and nonusers, significant at $P<0.05$.

Barratt et al found that 1019 of 2638 eligible staff members (38.6\%) had elevated blood cholesterol. ${ }^{27}$ Similarly, Fitzgerald et al found that $37 \%$ of Maryland workers who participated in a cholesterol screening had total cholesterol higher than $200 \mathrm{mg} / \mathrm{dl}^{28}$ Given the strong association between elevated

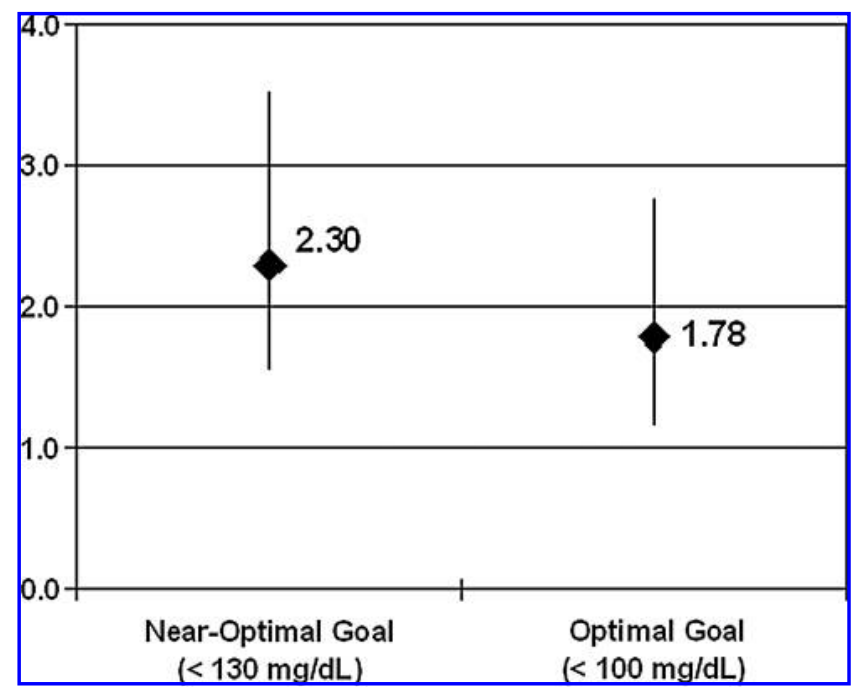

FIG. 2. Odds ratios of LDL-C goal achievement in executive statin users compared with statin nonusers.

cholesterol and the development of coronary artery disease, appropriate management of cholesterol among workplace populations is an opportunity to not only improve worker health but also to reduce future medical care expenditures.

However, results for workplace-based behavioral and dietary interventions have been mixed. For example, Wang et al reported that a single workplace cholesterol assessment could result in substantial modifications to CHD risk factors. ${ }^{29}$ Hartman et al also showed substantial effects of a workplace dietary intervention on lowering cholesterol. ${ }^{30}$ In contrast,

Table 4. Odds Ratios and 95\% Confidence Intervals of Achieving Low-Density Lipoprotein Cholesterol (LDL-C) Goal Among 1607 Executives With and Without Statin Therapy

\begin{tabular}{lcc}
\hline & Achieving $<130 \mathrm{mg} / \mathrm{dL}$ & $\begin{array}{c}\text { Achieving }<100 \mathrm{mg} / \mathrm{dL} \\
\text { OR }(95 \% \mathrm{CI})\end{array}$ \\
\hline Female $^{*}$ & OR $(95 \% \mathrm{CI})$ & $2.435(1.863,3.184)$ \\
Age in index year* & $2.296(1.816,2.903)$ & $0.970(0.952,0.988)$ \\
White & $0.969(0.954,0.984)$ & $0.818(0.546,1.226)$ \\
Work in Illinois & $1.111(0.774,1.595)$ & $1.002(0.742,1.354)$ \\
Index year* & $1.069(0.834,1.371)$ & \\
1995 & & 1.000 \\
1996 & 1.000 & $0.866(0.513,1.462)$ \\
1997 & $0.900(0.608,1.333)$ & $0.765(0.350,1.672)$ \\
1998 & $0.701(0.411,1.198)$ & $1.922(1.014,3.645)$ \\
1999 & $1.944(1.128,3.353)$ & $1.204(0.631,2.299)$ \\
2000 & $1.285(0.782,2.112)$ & $1.297(0.692,2.433)$ \\
2001 & $1.088(0.666,1.777)$ & $1.216(0.627,2.359)$ \\
2002 & $1.662(0.986,2.799)$ & $2.311(1.235,4.325)$ \\
2003 & $1.513(0.879,2.605)$ & $2.522(1.493,4.261)$ \\
2004 & $1.824(1.170,2.846)$ & $1.970(1.239,3.132)$ \\
Health condition & $2.027(1.400,2.933)$ & \\
CDS & & $1.021(0.941,1.109)$ \\
Had heart diseases* & $1.063(0.979,1.155)$ & $4.655(2.366,9.157)$ \\
Took diabetes meds & $2.978(1.397,6.350)$ & $1.294(0.439,3.815)$ \\
Received statin treatment* & $1.296(0.416,4.033)$ & $1.783(1.153,2.755)$ \\
\hline
\end{tabular}

*Significant at $P<0.05$.

OR, odds ratio; CI, confidence interval; CDS, chronic disease score. 
Table 5. Odds Ratios of Achieving Near-Optimal Low-Density Lipoprotein Cholesterol (LDL-C) Goal ( $<130 \mathrm{mg} / \mathrm{DL})$ ANd Optimal LDL-C GoAl ( $<100 \mathrm{Mg} / \mathrm{dL})$ Among 1607 Executives Adherent AND NONADHERENT to STATIN THERAPY

\begin{tabular}{lcc}
\hline & Achieving $<130 \mathrm{mg} / \mathrm{dL}$ & $\begin{array}{c}\text { Achieving }<100 \mathrm{mg} / \mathrm{dL} \\
\text { OR }(95 \% \text { CI })\end{array}$ \\
Explanatory variables & OR $(95 \% \mathrm{CI})$ & $2.433(1.860,3.181)$ \\
\hline Female* & $2.297(1.817,2.904)$ & $0.970(0.951,0.988)$ \\
Age in index year* & $0.969(0.954,0.984)$ & $0.824(0.550,1.236)$ \\
White & $1.103(0.769,1.583)$ & $0.995(0.737,1.345)$ \\
Work in Illinois & $1.077(0.839,1.381)$ & 1.000 \\
Index year* & & $0.872(0.516,1.472)$ \\
1995 & 1.000 & $0.764(0.350,1.669)$ \\
1996 & $0.894(0.604,1.325)$ & $1.921(1.013,3.641)$ \\
1997 & $0.702(0.411,1.201)$ & $1.209(0.633,2.308)$ \\
1998 & $1.951(1.131,3.365)$ & $1.317(0.702,2.470)$ \\
1999 & $1.277(0.777,2.099)$ & $1.217(0.627,2.361)$ \\
2000 & $1.068(0.653,1.747)$ & $2.350(1.255,4.403)$ \\
2001 & $1.659(0.985,2.795)$ & $2.548(1.507,4.306)$ \\
2002 & $1.483(0.860,2.558)$ & $1.935(1.214,3.083)$ \\
2003 & $1.803(1.155,2.813)$ & \\
2004 & $2.062(1.423,2.988)$ & $1.023(0.942,1.110)$ \\
Health condition & & $4.886(2.458,9.710)$ \\
CDS & $1.063(0.978,1.155)$ & $1.335(0.450,3.962)$ \\
Had heart diseases* & $2.822(1.316,6.055)$ & 1.000 \\
Took diabetes meds & $1.240(0.397,3.873)$ & $2.223(1.145,4.313)$ \\
Treatment adherence* & & $1.561(0.910,2.676)$ \\
No Statins & 1.000 & \\
Statin MPR $<80 \%$ & $1.700(0.884,3.268)$ & \\
Statin MPR $\geq 80 \%$ & $2.750(1.662,4.550)$ & \\
\hline
\end{tabular}

*Significant at $P<0.05$.

OR, odds ratio; $\mathrm{CI}$, confidence interval; CDS, chronic disease score; MPR, medication possession ratio.

other workplace behavioral and dietary interventions, such as the Take Heart II study, ${ }^{31}$ did not have a significant impact on cholesterol levels.

There are several potential opportunities for employers to assist their employees to achieve lipid-lowering goals. The focus of such interventions might include employee medication adherence education and value-based pharmaceutical benefit plan design. ${ }^{32,33}$ It is important to consider racial and ethnic disparities of the employee population when designing and implementing workplace prevention and screening programs for cardiovascular risks. ${ }^{34}$ Recent studies have demonstrated that partnerships with community pharmacists to address medication adherence for cardiovascular risks such as hypertension and LDL-C may be effective. ${ }^{35}$

Several studies have evaluated worksite programs to address cardiovascular risk factors. ${ }^{30,36,37,38,39}$ Success of such programs is mixed, with many programs able to reduce the cardiovascular risks of employees but others having less positive effects. Organizations would be wise to take steps to help employees maintain their low risks and reduce their high risks through appropriate benefit plans as well as population health management programs. Adherence to statins can help improve cardiovascular risks and has shown cost-effectiveness. An economic simulation model was used to determine the cost-effectiveness of statins among patients at high risk for $\mathrm{CHD} .{ }^{40}$ Applying the simulation to a health plan with 210,000 covered lives, including 9336 at high risk for cardiovascular disease, yielded a reduction in total costs of $\$ 1735$ per treated patient, assuming that $11 \%$ of high-risk patients took the medication.

However, statin medication adherence is affected by a number of factors. In one study patient population, adherence to statin treatment was significantly associated with larger prescription size (60-day supply vs. 30-day supply) even after controlling for age, sex, race, co-payment, comorbidities, and insurance status. ${ }^{41}$ Another study of statin adherence among patients with employer-sponsored health insurance found that lower co-payments were associated with higher levels of statin adherence. ${ }^{42}$ Specifically, a $\$ 10$ increase in co-payment was associated with a 1.8 percentage point reduction in probability of adherence for new users and a 3 percentage point reduction in probability of continuing adherence while holding all other variables constant. ${ }^{42}$ Similar results were found by Pedan et al in that each $\$ 10$ increase in statin copayment was associated with a $2.2 \%$ decrease in adherence. ${ }^{43}$ Other factors that have been shown to affect statin adherence include feelings about medical providers and belief in the benefit of the medication, ${ }^{44}$ perception of risk of myocardial infarction, and concern about statin side effects. ${ }^{45}$

\section{Limitations}

We acknowledge some limitations in this study. We have studied a convenience sample of executives whose demo- 
graphics do not reflect the overall employee population of the corporation and would not be generalizable to the general population. This financial services company has about $40 \%$ male employees and an average age of 39 years. This population was also more highly educated, predominantly white male and more highly compensated than the average employee. We would expect them to be more adherent with medication. Because their annual salary is at least $\$ 100,000$, the cost of medication is not an undue burden that would affect medication adherence. A future study of nonexecutive employees would be beneficial to determine whether the same compliance rates and goal achievement occurs.

The pharmacy benefit plan coverage for statins changed during the period of this study. It is known that the degree of employee cost-sharing for a prescription may be associated with medication adherence. ${ }^{46}$ It is not possible to evaluate such factors in the present study because of the small sample size in each study year. Finally, medication prescriptions may not equate with the employee actually taking the medication. However, the study is based on refilling the medication and it is unlikely that an individual would refill the medication and not take it.

\section{Conclusion}

This study found that statin usage appears to be associated with improvements in LDL-C among executives who participate in a PHE. Among all employees who received statin treatment, $70 \%$ achieved near-optimal $(<130 \mathrm{mg} / \mathrm{dL})$ and $30 \%$ achieved optimal $(<100 \mathrm{mg} / \mathrm{dL})$ goals for LDL-C, which is significantly more than the $55 \%$ and $21 \%$ achieved by statin nonusers. There was a progressive relationship showing that those who were adherent had the greatest likelihood of achieving lipid goal, and that those who took statins but did not meet the adherence criteria were significantly more likely to achieve their LDL-C goal than executives who did not take statins.

The employer as purchaser of health care has several opportunities to address the problem of lipid therapy medication adherence and achievement of lipid goals. Employees or family members who discontinue a lipid-lowering medication or fail to achieve optimal therapeutic goals result in potentially avoidable morbidity and mortality. Possible interventions include a value-based pharmaceutical benefit plan design, employee education, disease management programs that provide the counselor with MPR information for lipid-lowering medications, workplace wellness programs including screenings targeted at cardiovascular risk factor identification and reduction, among others. Such interventions should result in reduced direct and indirect cost trends for cardiovascular diseases to offset the incremental medication expenditures related to lipid-lowering therapy.

\section{Acknowledgments}

The authors wish to thank Kaan Tunceli, PhD and William Gerth, MBA, Global Outcomes Research, Merck \& Co., Inc. for their valuable contributions to the design and execution of this study and manuscript.

\section{Disclosure Statement}

This research was supported in part by an educational grant from Merck \& Co., Inc. Dr. Burton, Dr. Chen, Dr.
Schultz, and Dr. Edington disclosed no other conflicts of interest.

\section{References}

1. Centers for Disease Control and Prevention, Chronic Disease Prevention and Health Promotion. Heart disease and stroke prevention. Available at: http://www.cdc.gov/nccdphp/ publications/AAG/dhdsp.htm. Accessed October 2008.

2. National Cholesterol Education Program (NCEP) Expert Panel on Detection, Evaluation, and Treatment of High Blood Cholesterol in Adults (ATP III). Third Report of the National Cholesterol Education Program (NCEP) expert panel on detection, evaluation, and treatment of high blood cholesterol in adults (ATP III) final report. Circulation. 2002;106:3143-3421.

3. Nissen SE, Tuzcu EM, Schoenhagen P, et al. Effect of intensive compared with moderate lipid-lowering therapy on progression of coronary atherosclerosis: a randomized controlled trial. JAMA. 2004;291:1071-1080.

4. Cannon $\mathrm{CP}$, Braunwald $\mathrm{E}, \mathrm{McCabe} \mathrm{CH}$, et al. Intensive and moderate lipid lowering with statins after acute coronary syndromes. N Eng J Med. 2004;350:1495-1504.

5. Heart Protection Study Collaborative Group. MRC/BHF Heart Protection Study of cholesterol lowering with simvastatin in 20,536 high-risk individuals: a randomized placebocontrolled trial. Lancet. 2002;360:7-22.

6. Shepherd J, Cobbe SM, Ford I, et al. Prevention of coronary heart disease with pravastatin in men with hypercholesterolemia. N Engl J Med. 1995;333:1301-1307.

7. Law MR, Wald NJ, Rudnicka AR. Quantifying effect of statins on low density lipoprotein cholesterol, ischaemic heart disease, and stroke: systematic review and metaanalysis. BMJ. 2003;326:1423-1430.

8. Downs JR, Clearfield M, Weis S, et al. Primary prevention of acute coronary events with lovastatin in men and women with average cholesterol levels; results of AFCAPS/ TexCAPS. JAMA. 1998;279:1615-1622.

9. Sever PS. Dublof B, Poulter NR, et al. Prevention of cornonary and stroke events with atorvastatin in hypertensive patients who have average or lower-than-average cholesterol concentrations, in the Anglo-Scandinavian Cardiac Outcomes Trial-Lipid Lowering Arm (ASCOT-LLA): a muticentre randomized controlled trial. Lancet. 2003;361:1149-1158.

10. American Heart Association. Statistical fact sheet - risk factors. 2008 Update. Available at: http://www.americanheart .org/downloadable/heart/1197994908531FS16OVR08.pdf. Accessed October 2008.

11. Goldberg KC, Melnyk SD, Simel DL. Overcoming inertia: improvement in achieving target low-density lipoprotein cholesterol. Am J Manag Care. 2007;13:530-534.

12. McBride P, Schrott HG, Plane MB, Underbakke G, Brown RL. Primary care practice adherence to National Cholesterol Education Program guidelines for patients with coronary heart disease. Arch Intern Med. 1998;158:1238-1244.

13. Pearson TA, Laurova I, Chu H, Kafonek S. The Lipid Treatment Assessment Project (L-TAP): a multicenter survey to evaluate the percentages of dyslipidemic patients receiving lipid-lowering therapy and achieving low-density lipoprotein in cholesterol goals. Arch Intern Med. 2000;160:459-467.

14. Sloan KI, Sales AE, Willems JP, et al. Frequency of serum low-density lipoprotein cholesterol measurement and frequency of results $\leq 100 \mathrm{mg} / \mathrm{dl}$ among patients who had coronary events (Northwest VA Network Study). Am J Cardiol. 2001;88:1143-1146. 
15. Ford ES, Mokdad AH, Giles WH, Mensah GA. Serum total cholesterol concentrations and awareness, treatment and control of hypercholesterolemia among US adults: findings from the National Health and Nutrition Examination Survey. 1999-2000. Circulation. 2003;107:2185-2189.

16. Olson KI, Tsuyuki RT. Patients' achievement of cholesterol targets: a cross-sectional evaluation. Am J Prev Med. 2003; 25:339-342.

17. Olson KI, Bungard TI, Tsuyuki RT. Cholesterol risk management: a systematic examination of the gap from evidence to practice. Pharmacotherapy. 2001;21:807-817.

18. Nash DT. Dyslipidemia: time to treat as seriously as hypertension. Consultant. 1997;37:1915-1923.

19. Alfonso NM, Nassif G, Aranha AN, DeLor B, Cardozo LJ. Low-density lipoprotein cholesterol goal attainment among high-risk patients: does a combined intervention targeting patients and providers work? Am J Manag Care. 2006;12:589-594.

20. Mosca L, Linfante AH, Benjamin EJ, et al. National study of physician awareness and adherence to cardiovascular disease prevention guidelines. Circulation. 2005;111:499-510.

21. Rodondi N, Peng T, Karter AJ, et al. Therapy modifications in response to poorly controlled hypertension, dyslipidemia, and diabetes mellitus. Ann Intern Med. 2006;144:475-484.

22. Schedlbauer A, Schroeder K, Peters TJ, Fahey T. Interventions to improve adherence to lipid lowering medication (Review). Cochrane Database Syst Rev. 2004, Issue 4. Art. No.: CD004371. DOI: 10.1002/14651858.CD004371.pub2.

23. Burton WN, Hoy DA, Stephens M. A computer-assisted health care cost management system. J Occup Med. 1991;33: 268-271.

24. Burton WN, Chen C-Y, Conti DJ, Schultz AB, Edington DW. The value of the Periodic Executive Health Examination: experience at Bank One and summary of the literature. J Occup Environ Med. 2002;44:737-744.

25. Osterberg L, Blaschke T. Adherence to medication. N Engl J Med. 2005;353:487-497.

26. Clark DO, von Korff M, Saunders K, Baluch WM, Simon GE. A chronic disease score with empirically derived weights. Med Care. 1995;33:783-795.

27. Barratt A, Reznik R, Irwig L, et al. Worksite cholesterol screening and dietary intervention: the Staff Healthy Heart Project. Steering committee. Am J Public Health. 1994;84:779782.

28. Fitzgerald ST, Gibbens S, Agnew J. Evaluation of referral completion after a workplace cholesterol screening program. Am J Prev Med. 1991;7:335-340.

29. Wang JS, Carson EC, Lapane KL, Eaton CB, Gans KM, Lasater TM. The effect of physician office visits on CHD risk factor modification as part of a worksite cholesterol screening program. Prev Med. 1999;28:221-228.

30. Hartman TJ, Himes JH, McCarthy PR, Kushi LH. Effects of a low-fat, worksite intervention on blood lipids and lipoproteins. J Occup Environ Med. 1995;37:690-696.

31. Glasgow RE, Terborg JR, Strycker LA, Boles SM, Hollis JF. Take Heart II: replication of a worksite health promotion trial. J Behav Med. 1997;20:143-161.

32. Schedlbauer A, Schroeder, Fahey T. How can adherence to lipid-lowering medication be improved? A systematic review of randomized controlled trials. Fam Pract. 2007;24:380-387.

33. Schneeweiss S, Patrick AR, Maclure M, Dormuth CR, Glynn RJ. Adherence to statin therapy under drug cost sharing in patients with and without acute myocardial infarction; a population-based natural experiment. Circulation. 2007; 115:2128-2135.

34. Hertz RP, McDonald M, Unger AN, Lustik MB. Racial and ethnic disparities in the prevalence and management of cardiovascular risk factors in the United States workforce. J Occup Environ Med. 2007;49:1165-1175.

35. Lee JK, Grace KA, Taylor AJ. Effect of a pharmacy care program on medication adherence and persistence, blood pressure, and low-density lipoprotein cholesterol. JAMA. 2006;296:2563-2571.

36. Pegus C, Bazzarra TL, Brown JS, Menzin J. Effect of the Heart at Work Program on awareness of risk factors, selfefficacy, and health behaviors. J Occup Environ Med. 2002;44:228-236.

37. Bloch MJ, Armstron DS, Dettling L, Hardy A, Caterino K, Barrie S. Partners in lowering cholesterol: comparison of a multidisciplinary education program, monetary incentives, or usual care in the treatment of dyslipidemia identified among employees. J Occup Environ Med. 2006;48:675-681.

38. Aldana SG, Greenlaw R, Diehl HA, Englert H, Jackson R. Impact of the Coronary Health Improvement Project (CHIP) on several employee populations. J Occup Environ Med. 2002;44:831-839.

39. Aldana SG, Greenlaw RL, Diehl HA, Salberg A, Merrill RM, Ohmine S. The effects of a worksite chronic disease prevention program. J Occup Environ Med. 2005;47:558-564.

40. Song X, Huse D, Williams S, Borok G, McDonough K, Ozminkowski R. A projection of the impact of lipid-lowering rherapy on high-risk employee disability and medical costs. J Occup Environ Med. 2006;48:1014-1022.

41. Batal HA, Krantz MJ, Dale RA, Mehler PS, Steiner JF. Impact of prescription size on statin adherence and cholesterol levels. BMC Health Serv Res. 2007;7:175-180.

42. Gibson TB, Mark TL, Axelsen K, Baser O, Rublee DA, McGuigan KA. Impact of statin copayments on adherence and medical care utilization and expenditures. Am J Manag Care. 2006;12 spec no:SP11-SP19.

43. Pedan A, Varasteh L, Schneeweiss S. Analysis of factors associated with statin adherence in a hierarchical model considering physician, pharmacy, patient, and prescription characteristics. J Manag Care Pharm. 2007;13:487-496.

44. McGinnis B, Olson KL, Magid D, et al. Factors related to adherence to statin therapy. Ann Pharmacother. 2007;41: 1805-1811.

45. Mann DM, Allegrante JP, Natarajan S, Halm EA, Charlson $M$. Predictors of adherence to statins for primary prevention. Cardiovasc Drugs Ther. 2007;21:311-316.

46. Burton WN, Chen CY, Schultz AB, Edington DW. The association between a tiered pharmacy benefit plan and medication usage, health status, and disability absence days-one employer's experience. I Occup Environ Med. 2008;50:1176-1184.

Address correspondence to: Dee W. Edington, Ph.D.

University of Michigan Health Management Research Center 1015 E. Huron St. Ann Arbot, MI 48104-1688

E-mail:dwe@umich.edu 
This article has been cited by:

1. John Kucan, Ernest Bryant, Alan Dimick, Paula Sundance, Nathan Cope, Reginald Richards, Chris Anderson. 2010. Systematic Care Management: A Comprehensive Approach to Catastrophic Injury Management Applied to a Catastrophic Burn Injury Population-Clinical, Utilization, Economic, and Outcome Data in Support of the Model. Journal of Burn Care \& Research 31:5, 692-700. [CrossRef] 